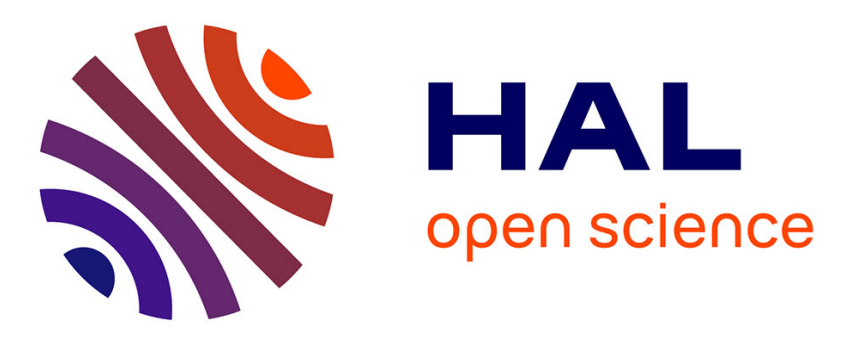

\title{
Arctic underwater noise transients from sea ice deformation: characteristics, annual time series, and forcing in Beaufort Sea
}

G Bazile Kinda, Yvan Simard, Cedric Gervaise, Jerome I. Mars, Louis Fortier

\section{- To cite this version:}

G Bazile Kinda, Yvan Simard, Cedric Gervaise, Jerome I. Mars, Louis Fortier. Arctic underwater noise transients from sea ice deformation: characteristics, annual time series, and forcing in Beaufort Sea. Journal of the Acoustical Society of America, 2015, 138 (4), pp.2034-2045. 10.1121/1.4929491. hal-01199284

\section{HAL Id: hal-01199284 \\ https://hal.science/hal-01199284}

Submitted on 15 Sep 2015

HAL is a multi-disciplinary open access archive for the deposit and dissemination of scientific research documents, whether they are published or not. The documents may come from teaching and research institutions in France or abroad, or from public or private research centers.
L'archive ouverte pluridisciplinaire HAL, est destinée au dépôt et à la diffusion de documents scientifiques de niveau recherche, publiés ou non, émanant des établissements d'enseignement et de recherche français ou étrangers, des laboratoires publics ou privés. 


\title{
Arctic underwater noise transients from sea ice deformation: characteristics, annual time series, and forcing in Beaufort Sea \\ G. Bazile Kinda ${ }^{\mathrm{a}, \mathrm{b}}$ \\ Université Grenoble Alpes, GISPA-LAB, 11 rue des Mathématiques, 38402 Saint-Martin d'Hères, France
}

Yvan Simard ${ }^{\text {c) }}$

Marine Science Institute, University of Québec at Rimouski, 310 Allée des Ursulines, Rimouski, QC, Canada G5L$3 \mathrm{~A} 1$

Cédric Gervaise ${ }^{\mathrm{d})}$

Chair Chorus, Foundation of Grenoble Institute of Technology, 46, Avenue Félix Viallet, 38031 Grenoble cedex 1, France

Jérôme I. Mars

Université Grenoble Alpes, GISPA-LAB, 11 rue des Mathématiques, 38402 Saint-Martin d'Hères, France

Louis Fortier

Canada Research Chair on the response of Arctic marine ecosystems to climate change, Québec-Océan, Department of biology, Laval University, Québec, QC, Canada G1V-0A6

\begin{abstract}
A 13-month time series of Arctic Ocean noise from the marginal ice zone of Eastern Beaufort Sea is analyzed to detect under-ice acoustic transients isolated from ambient noise with a dedicated algorithm. Noise transients due to ice cracking, fracturing, shearing, and ridging are sorted out into 3 categories: broadband impulses, frequency modulated (FM) tones, and high-frequency broadband noise. Their temporal and acoustic characteristics over the 8-month ice covered period, from November 2005 to mid-June 2006, are presented and their generation mechanisms are discussed. Correlations analyses showed that the occurrence of these ice transients responded to large-scale ice motion and deformation rates forced by meteorological events, often leading to opening of large-scale leads at main discontinuities in the ice cover. Such a sequence, resulting in the opening of a large lead, hundreds by tens $\mathrm{km}$ in size, along the margin of landfast ice and multiyear ice plume in Beaufort-Chukchi seas is detailed. These ice transients largely contribute to the soundscape properties of the Arctic Ocean, for both its ambient and total noise components. Some FM tonal transients can be confounded with marine mammal songs, especially when they are repeated, with periods similar to wind generated waves.
\end{abstract}

PACS numbers: 43.30.Nb, 43.50.Rq, 43.60.Cg

\footnotetext{
a) Corresponding author (email: bazile.kinda@gmail.com)

b) Now at: Lab-STICC (UMR CNRS 6285), ENSTA Bretagne (Université Européenne de Bretagne), 2 rue François Verny, 29806 Brest Cedex 9, France

c) Also at: Maurice Lamontagne Institute, Fisheries and Oceans Canada, 850 route de la Mer, Mont-Joli, QC, Canada G5H-3Z4

d) Also at: Université Grenoble Alpes, GISPA-LAB, 11 rue des Mathématiques, 38402 Saint-Martin d'Hères, France
} 


\section{Introduction}

Underwater soundscapes of high-latitude oceans and seas are strongly shaped by seasonal or permanent ice covers (e.g. Lewis and Denner (1987, 1988a, b), Kinda et al., (2013)). Although ice covers strongly dampen surface born underwater noise generated by wind/waves and precipitation, the dynamic response of ice to several environmental forcing processes introduces noise in the underwater environment. Under-ice ocean noise therefore reflects the regional response of its ice cover to environmental forcing. Ice spatial extent, thickness, structure, mechanical behavior, continuity and movement are all factors affecting the characteristics of underwater noise at several spatial and temporal scales. All these properties of the Arctic ice cap are rapidly changing in response to global warming (Marsan et al., 2012, 2004; Maslanik et al., 2011; Stroeve et al., 2012). Consequently, global warming should affect the present acoustic environment of the Arctic, whose soundscape temporal and spatial characteristics are still poorly known. The characterization of its present state is needed to establish the baseline before significant man made noise is introduced by increasing shipping and industrial development that are made possible by the melting of the ice.

The under-ice noise in Arctic Ocean in the last century has been shown to primarily originate from discrete acoustic events produced by the combination of thermal, wind and current stresses on the ice canopy (Milne and Ganton, 1964; Milne, 1966). Ice cracking events depend on the ice thickness and therefore the ice age. Xie and Farmer (1991) showed that these sources mainly originated from the heterogeneous multiyear ice zone in their study area. Thermal cracking sources radiate both acoustic energy in the water and induce seismic waves into the ice sheet (Xie and Farmer, 1995). Particular acoustic transients are generated at pressure and shear ridges (Buck and Wilson, 1986). Pure tones observed during ice break-up in the marginal ice zone (MIZ) were attributed to ice plate shearing and rubbing that induced ice resonance whose frequency depends on the ice thickness and the shear speed (Xie and Farmer, 1992). Cummings et al. (1989) summarized other types of acoustic transients observed in very shallow waters $(\sim 8 \mathrm{~m})$ in the MIZ, such as ice squeaks, colliding crystals and bumps of ice chunk or ice floes, lead openings, snow pelting, wave slaps. The merging of a myriad of such acoustic transients originating from large areas results in stationary Gaussian ambient noise background (Veitch and Wilks, 1985). Following NRC (2003), we call "ambient noise" this diffuse background component of the soundscape, which level (ANL) can be extracted and estimated using proper signal processing algorithms (cf. Section II-B, Kinda et al., 2013). Ocean noise level $(\mathrm{ONL})$ is used to refer to the total noise, the sum of ANL + all transients sounds from physical or biological sources (NRC, 2003).

The under-ice ANL time series in the MIZ of Canadian Arctic in Eastern Beaufort Sea was found to be governed by large-scale ice drift entrained by the Beaufort Gyre and to respond to 7-day wind-forced pulses from the passing of meteorological depressions (Kinda et al., 2013). The present paper complements this previous study by analysing the under-ice transient noise time series and their environmental forcing. Three ice noise transient classes are characterized and their relations with sea ice conditions and dynamics, and meteorological forcing are studied. A detailed example is provided for a mid-winter wind-driven opening of a large-scale lead in the Beaufort Sea MIZ. Statistics are provided to assess the underwater sound exposure levels (SEL) associated with the three types of natural acoustic sources in the study area.

The paper is organized as follows. The next section presents the data set and the numerical analysis. The third section presents the results showing a detailed description of each transient class, their time series, 
and their relations with the environmental forcings. The last section discusses the results in terms of noise transient forcing mechanisms and contributions to characterizing the underwater soundscapes of the Arctic Ocean

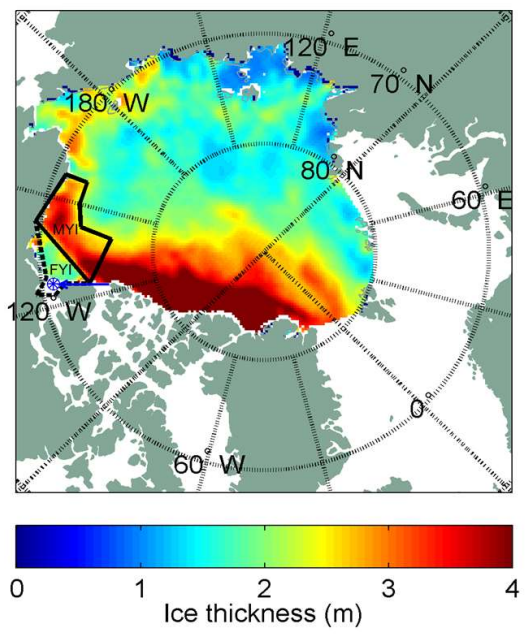

FIG 1. Polar map of Arctic sea ice thicknesses on February-March 2006 at maximum ice coverage . MYI zone; FYI zone; star: mooring location at the mouth of the Amundsen Gulf. Beaufort-Chukchi sea area limits were: [67.5_N $<$ latitude $\left.<80_{-} \mathrm{N}\right]$ and $\left[110_{-}\right.$ $\mathrm{W}<$ longitude $<180$ W $]$. The blue arrow points to the mooring position. the Amundsen Gulf. BeaufortChukchi sea area limits were: [67.5_N $<$ latitude $<80$ $\mathrm{N}]$ and $\left[110_{-} \mathrm{W}<\right.$ longitude $\left.<180_{-} \mathrm{W}\right]$. The blue arrow points to the mooring position.

\section{MATERIALS AND METHODS}

\section{A. The dataset}

The dataset is described in Kinda et al. (2013) . It consists in a 13-month time series of [2.0 Hz $4.096 \mathrm{kHz}$ ] 16-bit recordings for $7 \mathrm{~min}$ every hour from an autonomous underwater recorder (AURAL-M2 ${ }^{1}$ ) attached to an oceanographic mooring at $\sim 52 \mathrm{~m}$ depth. The mooring was located at the mouth of the Amundsen Gulf ( $71^{\circ} 00.493$ ' N, $126^{\circ} 04.230^{\prime}$ W) in Eastern Beaufort Sea (Fig. 1) at a water depth of 397 $\mathrm{m}$. The recordings lasted 384 days, from September 9, 2005, to October 2, 2006. The under-ice period (ice concentration $>90 \%$ in a radius of $100 \mathrm{~km}$ around the station) lasted 230 days, from November 6 to June 23. The meteorological and ice data come from several public sources (Table 1).

TABLE I. Sources and characteristics of environmental variables used for the analysis.

\begin{tabular}{|l|c|c|}
\hline \multicolumn{1}{|c|}{ Source } & Variable & Resolution \\
\hline $\begin{array}{c}\text { Environment } \\
\text { Canada }\end{array}$ & $\begin{array}{c}\text { Wind speed and direction, air temperature and precipitations at } \\
\text { Cape Parry, Amundsen Gulf, Eastern Beaufort Sea, }\left(70^{\circ} 00.17^{\prime} \mathrm{N},\right. \\
\left.124^{\circ} 00.72^{\prime} \mathrm{W}\right), 80 \mathrm{~km} \text { from the recording station }\end{array}$ & Hourly or daily \\
\hline \multirow{2}{*}{ ICDC } & Ice concentration & Daily \\
& Ice thickness in Oct.-Nov. 2005 and Feb.-March 2006. & $6.25 \times 6.25 \mathrm{~km}$ \\
& & $25 \times 25 \mathrm{~km}$ \\
\hline NSIDC & Ice drift & Daily \\
& & $25 \times 25 \mathrm{~km}$ \\
\hline
\end{tabular}

\footnotetext{
1 http://www.multi-electronique.com/ (Last viewed 2015/07/21).
} 


\section{B. Numerical analysis}

Wind speed was decomposed into its along-shore (positive east) and cross-shore (positive north) components. Sea ice deformation rates (Kwok, 2001; Rampal et al., 2008; Kwok and Cunningham, 2012) were computed for each node of the Arctic ice drift field as follows:

$$
\begin{aligned}
\zeta & =\frac{\partial v}{\partial x}-\frac{\partial u}{\partial y} \\
\nabla d & =\frac{\partial u}{\partial x}+\frac{\partial v}{\partial y} \\
s & =\left[\left(\frac{\partial u}{\partial x}-\frac{\partial v}{\partial y}\right)^{2}+\left(\frac{\partial u}{\partial y}+\frac{\partial v}{\partial x}\right)^{2}\right]^{1 / 2} \\
\tau & =\left[d^{2}+s^{2}\right]^{1 / 2}
\end{aligned}
$$

where, $u$ and $v$ are the east-west and north-south components of the ice drift speed at the coordinates $(x, y), \zeta$ the vorticity, $d$ the divergence, $s$ the shear deformation rate, and $\tau$ the total deformation rate of the ice velocity field. A mean ice deformation index $(\bar{\tau})$ was computed by averaging the total deformation rate estimated at each node of the NSIDC ice velocity field data, which are given with a resolution of $25 \mathrm{x}$ $25 \mathrm{~km}$ (Table 1). A large-scale $\bar{\tau}$ was computed for the Beaufort-Chukchi seas area (Fig. 1). Smaller-scale $\bar{\tau}$ were computed separately for the multi-year ice (MYI) plume and the first-year ice (FYI) areas near the recording station (Fig. 1) to account for their possible different contributions to noise (Xie \& Farmer, 1991, Kinda et al., 2013). The total ice-free area was computed as the sum of the product of the ice bin area (A) times the complement of its ice covered fraction $\left(\sum_{x, y} A \times(1-i c e\right.$ covered fraction $\left.)\right)$.

The raw 16-bit acoustic recordings were converted to instantaneous sound pressure levels (SPL) using the AURAL A/D conversion parameters, gain, and the receiving sensitivity of the hydrophone from calibration curves (see Kinda et al., 2013). Spectrograms of the 7-min hourly recordings were computed using a Hamming window of 2048 points, with $50 \%$ overlap. The low frequencies $(<\sim 100 \mathrm{~Hz})$ were sometimes contaminated by periodic strums from the mooring and hydrophone acceleration. Signal portions contaminated with such pseudo noise were recognizable by regular low-frequency pulses of variable bandwidth (Kinda et al., 2013); these bad data were handled as missing data in further processing. The presence of acoustic transients in the 7-min hourly acoustic recording was manually noted by visually examining the spectrograms. The beginning and end of a transient were given by the times when the transient exceeded the estimated ANL (see below). Most of the transients fall into one of the three transient classes considered as: broadband (BB) (class 1, Fig. 2), frequency modulated (FM) tones (class 2, Fig. 3) and high-frequency broadband (HFBB) $(>\sim 1 \mathrm{kHz})$ (class 3, Fig. 4). Their daily occurrence was computed as the number of 7-min hourly recordings with transients. The duration, the SPL, and the frequency characteristics of the transients for each class were estimated for $40 \%$ of the detected transients, uniformly distributed throughout the time series. The received levels were then computed as:

$$
S P L(d B \text { re } 1 \mu P a)=10 \times \log _{10}\left(\frac{1}{T} \int_{T} s^{2}(t) d t\right),(2)
$$

where SPL is the sound pressure level, $\mathrm{T}$ is the integration time corresponding to the transient duration, $\mathrm{s}(\mathrm{t})$ the transient signal expressed in $\mu P a$. For class 2 and class 3 transients, the acoustics signals were first 
filtered using bandpass or highpass filters with cutoff frequencies adapted to each transient. These filter cutoff frequencies were then used to compute the bandwidth and starting frequency statistics for these transient classes. The peak frequency of class 1 transients was read from the power spectral density (psd) expressed as the periodogram of the transient.

Generally, ocean noise consists of occasional transients superimposing a slowly varying background noise (i.e. ANL). The later component, was assumed to be Gaussian and stationary during a 7-min recording duty cycle. For each frequency bin of the spectrogram, the energy of a Gaussian ANL follows a Chi-2 distribution with two degrees of freedom. When present, transients have levels that exceed the ANL. Therefore the ANL can be estimated for each frequency bin by the lowest coefficients of the spectrogram, whose cumulative density function allows an accurate estimation of the parameters of the Chi-2 distribution of the ANL. The psd of the ambient noise at that frequency bin is given by the variance of the Chi-2 distribution. This is repeated for all frequency bins. For more details, see the appendix in Kinda et al. (2013).

The ANL and ONL of the 7-min recordings where transients were present were computed following (Eq.3), $O N L(d B$ re $1 \mu P)=10 \times \log _{10}\left(\frac{1}{T_{r}} \int_{T_{r}} m^{2}(t) d t\right)$,

where, $\mathrm{T}_{\mathrm{r}}$ refers to the recording time (420 s, the duration of the acoustic recording sequence), and $\mathrm{m}(\mathrm{t})$ to the whole ocean noise expressed in $\mu P a$. The contribution of the transients to the total noise relative to the ambient background (ANL) is: ONL-ANL (in $\mathrm{dB}$ ) (i.e. $10^{(\mathrm{ONL}-\mathrm{ANL}) / 10}$ on a linear scale).

The sound exposure level estimated for one hour $\left(\mathrm{SEL}_{\mathrm{h}}\right)$ is:

$$
S E L_{h}\left(d B \text { re } 1 \mu P a^{2} \cdot s\right)=O N L+10 \times \log _{10}(3600),
$$

The daily averaged $\overline{\mathrm{SEL}_{\mathrm{h}}}$ is :

$$
\overline{S E L_{h}}\left(d B \text { re } 1 \mu P a^{2} \cdot s\right)=10 \times \log _{10}\left(\frac{1}{24} \sum_{24} 10^{S E L_{h} / 10}\right),
$$

The relations between the transient occurrences and the environmental variables were examined through correlations and principal component analyses (PCA, Legendre and Legendre, 1998) using daily data. The PCA were performed on correlation matrices so that all considered variables have the same weight in the analysis.

\begin{tabular}{|c|c|c|c|c|c|c|c|c|}
\hline & Mean \pm e.s.d & Min & $5 \%$ & $25 \%$ & $50 \%$ & $75 \%$ & $95 \%$ & Max \\
\hline Durations (s) & $51.7 \pm 89.62$ & 0.9 & 2.7 & 7.13 & 17.0 & 43.2 & 282.3 & $>420$ \\
\hline $\mathrm{SPL}^{\mathrm{a}}(\mathrm{dB}$ re $1 \mu \mathrm{Pa})$ & $103.9 \pm 6.1$ & 91.5 & 95.5 & 99.6 & 102.8 & 107.0 & 114.7 & 136.9 \\
\hline Peak frequency $(\mathrm{Hz})$ & $66 \pm 137$ & 16 & 16 & 16 & 32 & 48 & 265 & 1344 \\
\hline $\mathrm{ANL}^{\mathrm{b}}(\mathrm{dB}$ re $1 \mu \mathrm{Pa})$ & $96.4 \pm 5.2$ & 90.2 & 90.4 & 92.3 & 95.3 & 99.4 & 106.9 & 118.7 \\
\hline $\mathrm{ONL}^{\mathrm{b}}(\mathrm{dB}$ re $1 \mu \mathrm{Pa})$ & $97.6 \pm 6.2$ & 90.2 & 90.6 & 92.8 & 96.0 & 100.6 & 111.0 & 120.0 \\
\hline $\mathrm{ONL}^{-\mathrm{ANL}^{\mathrm{b}}(\mathrm{dB})}$ & $1.3 \pm 2.1$ & 0 & 0.05 & 0.2 & 0.5 & 1.2 & 5.5 & 20.4 \\
\hline $\mathrm{SELh}_{\mathrm{h}}(\mathrm{dB}$ re $1 \mu \mathrm{Pa} . \mathrm{s})$ & $115 \pm 6.2$ & 107.1 & 107.6 & 110.6 & 114.3 & 119.4 & 128.7 & 132.6 \\
\hline
\end{tabular}

TABLE II. Statistical characteristics of the BB transients $(n=1050)$.

${ }^{\text {a }}$ Computed in the $[0-4.1 \mathrm{kHz}]$ frequency band over the transient duration.

${ }^{\mathrm{b}}$ Computed in the $[0-4.1 \mathrm{kHz}]$ frequency band for $7 \mathrm{~min}$. 


\section{Results}

\section{A. Class 1: BB transients}

BB transients sometimes covered the entire 7-min hourly recordings (Fig. 2, Table II). They were present $10.6 \%$ of the time (i.e 584/5496 hourly recordings). Their frequency peak was skewed towards very low-frequency $(75 \%<50 \mathrm{~Hz}$, Table II), with higher frequency peaks on occasions $(5 \%>265 \mathrm{~Hz})$ but never exceeding $1.4 \mathrm{kHz}$. The energy band was usually below $1 \mathrm{kHz}$ (e.g. Fig. 2c, d), with extensions to higher frequencies during loud sequences (Fig. 2a, b). Their duration was variable, ranging from $\sim 0.9 \mathrm{~s}$ to the whole 7-min hourly recording. Half of them lasted less than $17 \mathrm{~s}$ and only $5 \%$ exceeded $4.3 \mathrm{~min}$. The broadband received levels of these transients averaged $104 \mathrm{~dB}$ re $1 \mu P, 90 \%$ of them ranged between 95.5 and $107.0 \mathrm{~dB}$ re $1 \mu P a$ and the maximum peaked at $136.9 \mathrm{~dB}$ re $1 \mu P a$.

\section{B. Class 2: FM tonal transients}

FM tonal transients of variable duration and frequency, and presenting several harmonics that sometimes extended across the entire recorded bandwidth (Fig. 3a,b) were common (Fig. 3, Table III). They appeared and disappeared abruptly (Fig. 3b,c,e), and sometimes repeated at regular intervals (Fig. 3f). These transients were encountered in $22.3 \%$ of the hourly recordings. Their duration was highly variable, averaged $189.6 \pm 149.2 \mathrm{~s}$, and ranged from $1 \mathrm{~s}$ to $\geq 420 \mathrm{~s}$, the duration of a recording sequence. Their average frequency band was much higher than the BB transient class. Half of the transients were within a [1-3 kHz] envelope and less than $5 \%$ were $<500 \mathrm{~Hz}$ or $>4 \mathrm{kHz}$. The received levels averaged $95 \mathrm{~dB}$ re $1 \mu \mathrm{Pa}$, and $90 \%$ were within a $21-\mathrm{dB}$ envelope around this mean value. Because of their low levels and the general trend of decreasing levels with frequency, these transients did not contribute as much as BB transients to the low-frequency dominated broadband ONL.

\section{Class 3: HFBB transients}

HFBB transient class includes quasi-continuous events (Fig. 4a) or pulsed patterns similar to the FM tonal transients (Fig. 4b,d). They are easily recognizable by their long duration and elevated mean psd levels above $\sim 1 \mathrm{kHz}$, which reach a plateau at $\sim 2 \mathrm{kHz}$ (e.g. Fig. 4c), but possibly extend above our sampling limit of $4.1 \mathrm{kHz}$. Half of the transient starting frequency was within a $[1.05-1.67 \mathrm{kHz}]$ envelope, the median was $1.5 \mathrm{kHz}$, and less than $5 \%$ started below $587 \mathrm{~Hz}$ (Table IV). Such HFBB transients were encountered $18.5 \%$ of the time. They generally covered the entire 7-min hourly recordings (Fig. 4a,b). Their broadband levels were narrowly distributed around a mean of $92 \mathrm{~dB}$ re $1 \mu \mathrm{Pa}$, with $90 \%$ of the distribution centered within a $\sim 11-\mathrm{dB}$ envelope (Table IV). As for FM tonal transients, these weak HFBB transients contributed little to the broadband ANL and ONL. 
TABLE III. Statistical characteristics of the FM tonal transients ( $n=977)$.

\begin{tabular}{|l|c|c|c|c|c|c|c|c|}
\hline & Mean \pm e.s.d & Min & $5 \%$ & $25 \%$ & $50 \%$ & $75 \%$ & $95 \%$ & Max \\
\hline Durations $(\mathrm{s})$ & $189.6 \pm 149.2$ & 1.0 & 18.1 & 55.3 & 120.0 & 359.4 & 419.6 & $>420$ \\
\hline SPL $(\mathrm{dB}$ re $1 \mu \mathrm{Pa})$ & $95 \pm 6.5$ & 75.5 & 85.6 & 90.6 & 94.7 & 98.9 & 106.6 & 130.0 \\
\hline Bandwidth $(\mathrm{Hz})$ & $2032 \pm 1013$ & 139 & 544 & 1095 & 1813 & 2910 & 4024 & 4086 \\
\hline ANL $^{\text {b }}(\mathrm{dB}$ re $1 \mu \mathrm{Pa})$ & $91.7 \pm 5.1$ & 75.9 & 84.1 & 88.2 & 91.3 & 94.7 & 100.3 & 114.9 \\
\hline ONL $^{\mathrm{b}}(\mathrm{dB}$ re $1 \mu \mathrm{Pa})$ & $97.3 \pm 5.6$ & 90.2 & 90.7 & 93.3 & 96.3 & 99.9 & 108.4 & 125.7 \\
\hline $\mathrm{ONL}_{-} \mathrm{ANL}^{\mathrm{b}}(\mathrm{dB})$ & $0.9 \pm 1.5$ & 0 & 0.03 & 0.1 & 0.4 & 0.9 & 3.4 & 14.4 \\
\hline $\mathrm{SEL}_{\mathrm{h}}(\mathrm{dB}$ re $1 \mu \mathrm{Pa} . \mathrm{s})$ & $115.9 \pm 6.0$ & 107.1 & 107.8 & 111.2 & 114.9 & 119.7 & 128.8 & 132.6 \\
\hline
\end{tabular}

${ }^{\text {a }}$ Computed using bandpass filtering adapted to each transient.

${ }^{\mathrm{b}}$ Computed in the $[0-4.1 \mathrm{kHz}]$ frequency band for $7 \mathrm{~min}$.
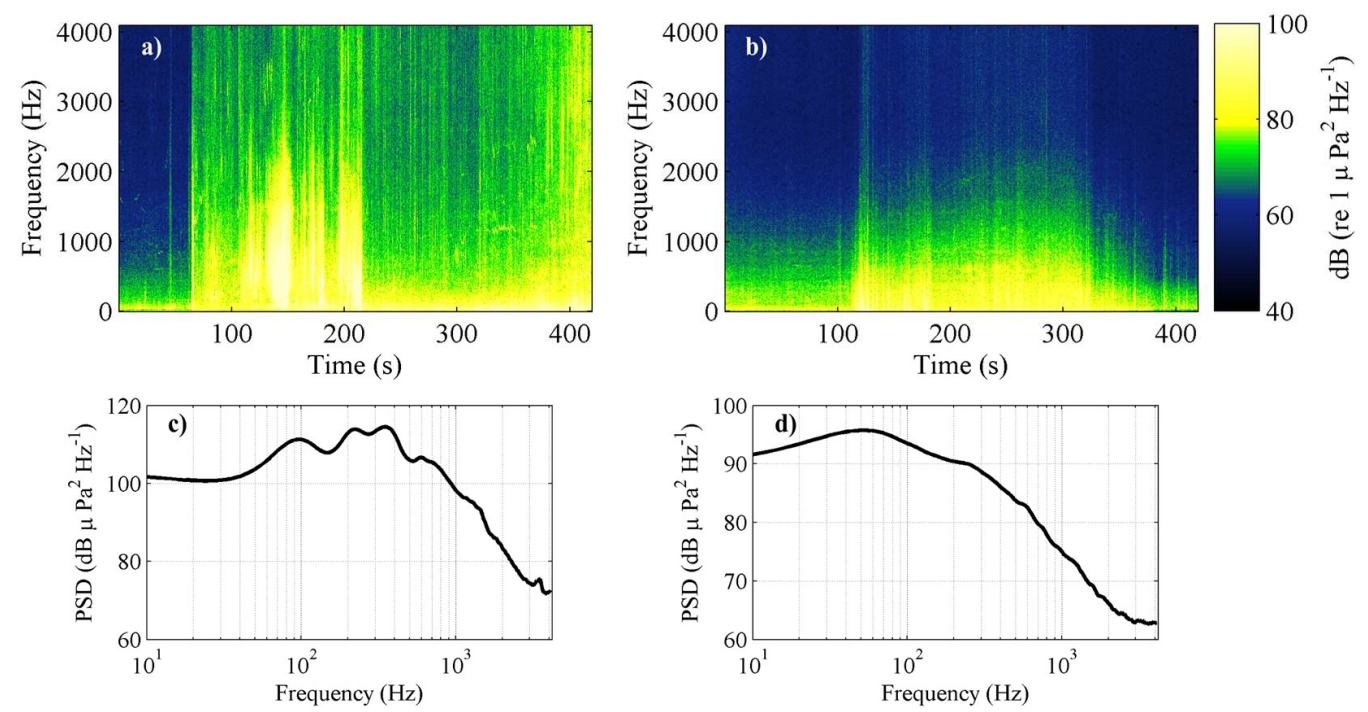

FIG 2. (Color online) Spectrograms of wideband transients observed on (a) December 15, 2005 at 17:00 (local time GMT-7) and (b) on February 6 , 2006 at 00:00 with their respective average psd[(c) and (d)]

\section{Time series and correlations with environmental variables}

Until the end of April, air temperature fluctuated between $-36.4^{\circ} \mathrm{C}$ and $-6.5^{\circ} \mathrm{C}$ around a mean of $20.5^{\circ} \mathrm{C}$. Positive temperatures occurred after May 11, which corresponded to the start of the ice break-up and coincided with a period of lower daily changes in air pressure (Fig. 5a,c, Table V). Air pressure and wind speed mainly oscillated with a $\sim 7$-day period (cf. Kinda et al., 2013). Other wind speed fluctuations followed a $\sim$-day cycle. Dominant winds were directed along the general coast line (east-west, Fig. $5 \mathrm{c}$ ), which is approximately the longitudinal axis of the Amundsen Gulf (Fig. 1). The recurrent declines of the ice concentration in the first $100-\mathrm{km}$ radius around the recording station is the evidence of frequent occurrences of open waters at the mouth of the Amundsen Gulf during winter (Fig. 5e). These open waters can represent as much as $10 \%$ of the surface (ex. February 13, Fig. 5f). Mean ice deformation rates in FYI and MYI zones were highly correlated (Pearson $r=0.79$, Table V) and $\sim 20 \%$ lower in the FYI zone (mean \pm e.s.d: $0.41 \pm 0.23 \mathrm{~s}^{-1}$ compared to $0.52 \pm 0.23 \mathrm{~s}^{-1}$ ). They were marked by large pulses, doubling or tripling the minimum deformation rate in winter, before steadily decreasing with the spring warming (Fig. $5 \mathrm{~d}$ ). The mean acoustic energy received hourly at the recording station, $\overline{\mathrm{SEL}_{\mathrm{h}}}$, and the occurrence of all transients 
also exhibited large fluctuations during winter with a general decrease during the spring warm-up ice melting and declining ice deformation (Fig. 5f-i). All variables except wind speed were slightly but significantly negatively correlated with air temperature (Table IV). Wind speed was significantly positively correlated with ice deformation, $\overline{\mathrm{SEL}_{\mathrm{h}}}$, and transient occurrences, and negatively correlated with the ice concentration. $\overline{S^{2} L_{h}}$ was significantly correlated with all transient occurrences (Pearson $r \geq 0.79$ ) and with ice shear and deformation rates in MYI and FWI (Pearson $r \geq 0.50$ and 0.43 respectively). The highest correlation of wind speed with transient occurrences was with HFBB transients (Pearson $r=0.44$ ). The ice divergence rates in both MYI and FYI areas significantly decreased with increasing air pressure (Pearson $r$ $=-0.3$ ). The occurrences of the three transient classes were significantly inter-correlated. They all significantly responded to increases in ice deformation rates, with slightly higher coefficients with MYI compared to FYI, and lower coefficients for BB transients (Table V).
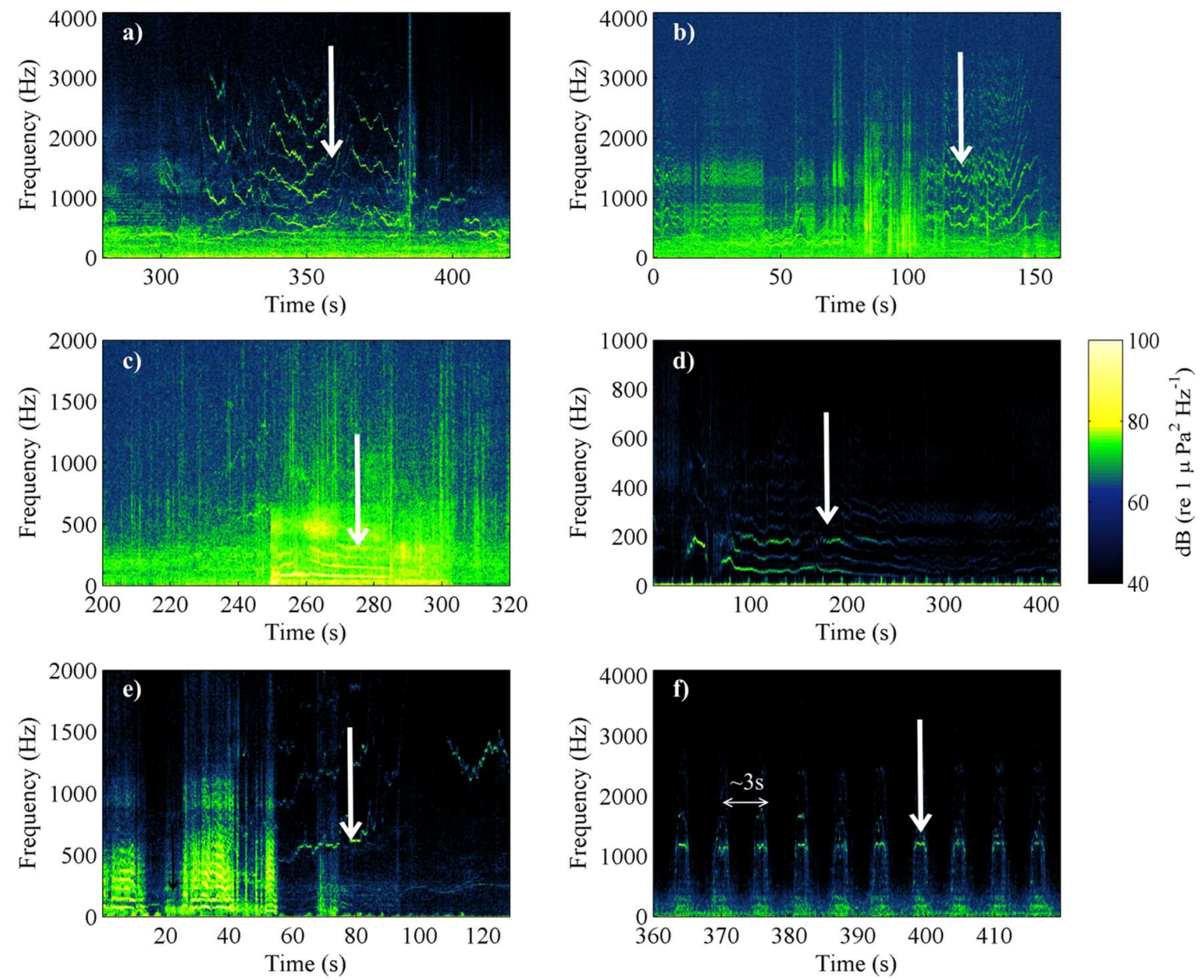

FIG 3. (Color online) Spectrograms of FM tonal transient recordings from February 12, 2006 [(a)-(e)] and March 19, 2006 (f). Note the numerous harmonics, the large frequency band, and regular pulsed pattern at_3-s intervals in (f). 

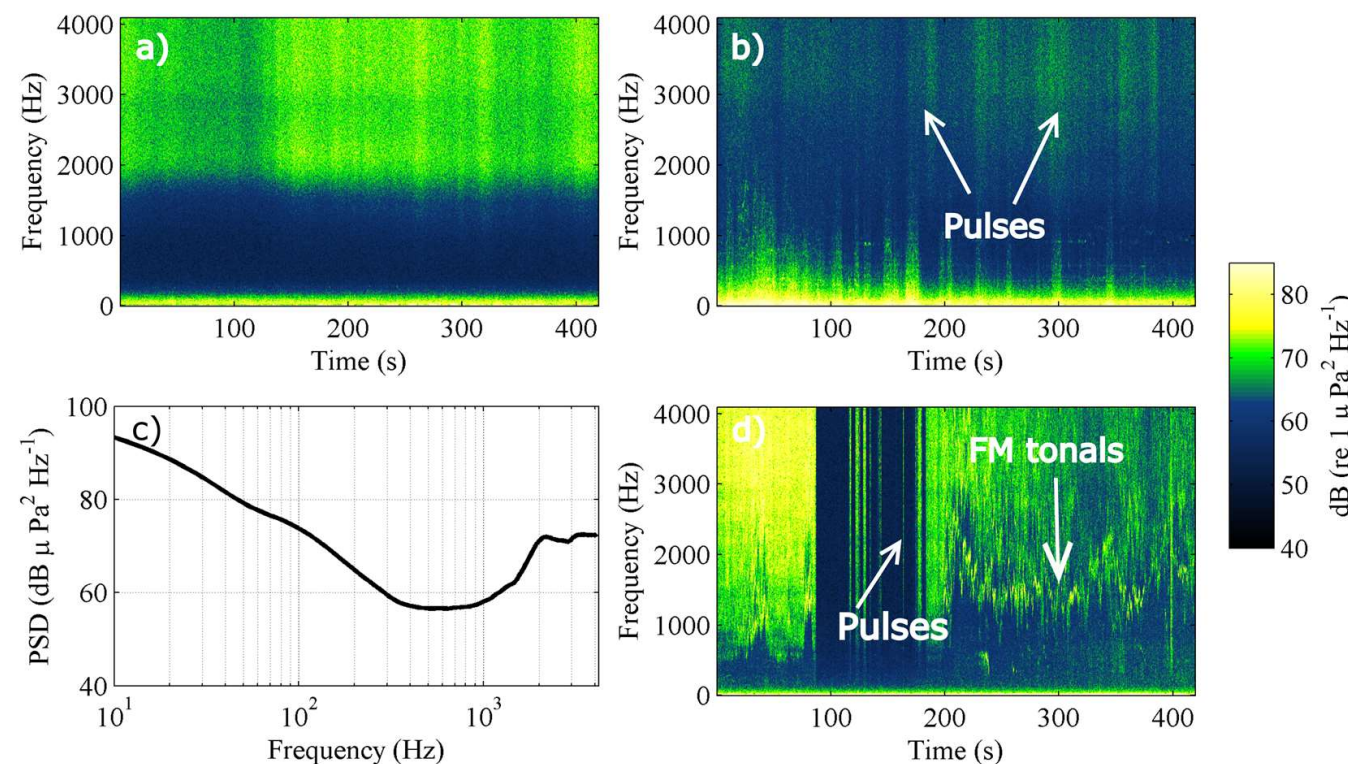

FIG 4. (Color online) Spectrogram of 7-min hourly recordings from February 12, 2006 showing: (a) HFBB transients with almost constant level, (b) HFBB transients with pulsed levels, (c) average psd of the recording in (a), and (d) discontinuous HFBB transients with FM tones.

TABLE IV. Statistical characteristics of the HFBB transients $(n=313)$.

\begin{tabular}{|c|c|c|c|c|c|c|c|c|}
\hline & Mean士e.s.d & Min & $5 \%$ & $25 \%$ & $50 \%$ & $75 \%$ & $95 \%$ & Max \\
\hline Durations (s) & \multicolumn{8}{|c|}{$\geq 420$} \\
\hline $\mathrm{SPL}^{\mathrm{a}}(\mathrm{dB}$ re $1 \mu \mathrm{Pa})$ & $92.9 \pm 3.7$ & 86.4 & 88.9 & 90.6 & 92.4 & 95.4 & 99.0 & 111.3 \\
\hline Starting freq. (Hz) & $1428 \pm 484$ & 130 & 587 & 1047 & 1488 & 1674 & 2287 & 3000 \\
\hline $\mathrm{ANL}^{\mathrm{b}}(\mathrm{dB}$ re $\mu \mathrm{Pa})$ & $97.8 \pm 5.0$ & 90.1 & 91.6 & 94.2 & 96.7 & 100.9 & 106.7 & 120.1 \\
\hline $\mathrm{ONL}^{\mathrm{b}}(\mathrm{dB}$ re $1 \mu \mathrm{Pa})$ & $99.4 \pm 6.2$ & 90.2 & 91.9 & 94.7 & 97.9 & 102.6 & 111.1 & 129.2 \\
\hline $\mathrm{ONL}^{-\mathrm{ANL}^{\mathrm{b}}(\mathrm{dB})}$ & $0.4 \pm 1.0$ & 0 & 0 & 0.03 & 0.10 & 0.4 & 1.3 & 10.6 \\
\hline $\mathrm{SELh}_{\mathrm{h}}(\mathrm{dB}$ re $1 \mu \mathrm{Pa} . \mathrm{s})$ & $116.1 \pm 1.0$ & 107.1 & 108.1 & 110.6 & 114.1 & 119.7 & 130.0 & 134.4 \\
\hline
\end{tabular}

${ }^{\text {a }}$ Computed using highpass filtering adapted to each transient

${ }^{\mathrm{b}}$ Computed in the $[0-4.1 \mathrm{kHz}]$ frequency band for $7 \mathrm{~min}$

The first two principal components of the PCA performed on the environmental variables explained $51.9 \%$ of their total variance. The scores in the plan of these first two principal components were colorcoded according to the daily transient occurrences, separately for the three transient classes (Fig. 6). The occurrence of all transient classes was sorted out by the first component, which explained $\sim 29 \%$ of the environmental variance (Fig. 6a,b,c). The highest transient occurrences were found in the positive part of this axis, which comprised more than $65 \%$ of the hourly occurrences. The PCA factor loadings (Fig. 6, arrows) indicate that the high transient occurrences corresponded to high shear rate in both MYI and FYI areas, high wind speeds, and lower air temperatures. The transients tended to be absent during low winds, low ice deformation rates, and high air temperatures (Fig. 6). The second component did not significantly categorize the transient occurrences, which were roughly equally distributed in the upper or lower quadrants without any clear trend. The variables that contributed the most to this axis were ice divergence rate, air pressure and ice concentration to a certain extent. 
The common sudden raises of $\overline{\mathrm{SEL}_{\mathrm{h}}}$ by 10 to $25 \mathrm{~dB}$ during winter (Fig. $5 \mathrm{f}$ ) sometimes corresponded to peaks in MYI deformation rates (Fig. $5 \mathrm{~d}$, Pearson $\mathrm{r} \geq 0.5$, Table V) that occurred with simultaneous or lagging reductions of the local ice concentration, indicating the opening or growth of leads within the ice cover (Fig. 5e). An example of this process is detailed below in examining a 45-day mid-winter segment of the time series (Fig. 7, 8, and daily sequence ice concentration and deformation maps not shown).

\section{E. Acoustic transients during extensive lead openings}

The spectrogram highlights several episodes of strong acoustic transients, particularly from January 21 to 25 (Fig. 7a), February 6, and February 9 to 15 (Fig. 7b). These periods of high transient occurrences started during or one day after large-scale mean ice deformation increased in Beaufort-Chukchi seas basin (Fig. 7a-1, a-2, a-3, and map time series not shown). The strongest of them, coinciding with offshore directed easterly winds (Fig. 5c), resulted in the opening of large-scale leads (Fig. 5e, 7b-1, b-2,b-3 and map time series not shown), especially along the MIZ margin, from Bering Strait to Banks Island, north of Amundsen Gulf (e.g. Fig. 8b). These large leads lasted for a few days before closing and eventually re-opening during favorable winds (cf. sequence from 5-15 February, Figs. 5 and map time series not shown). 


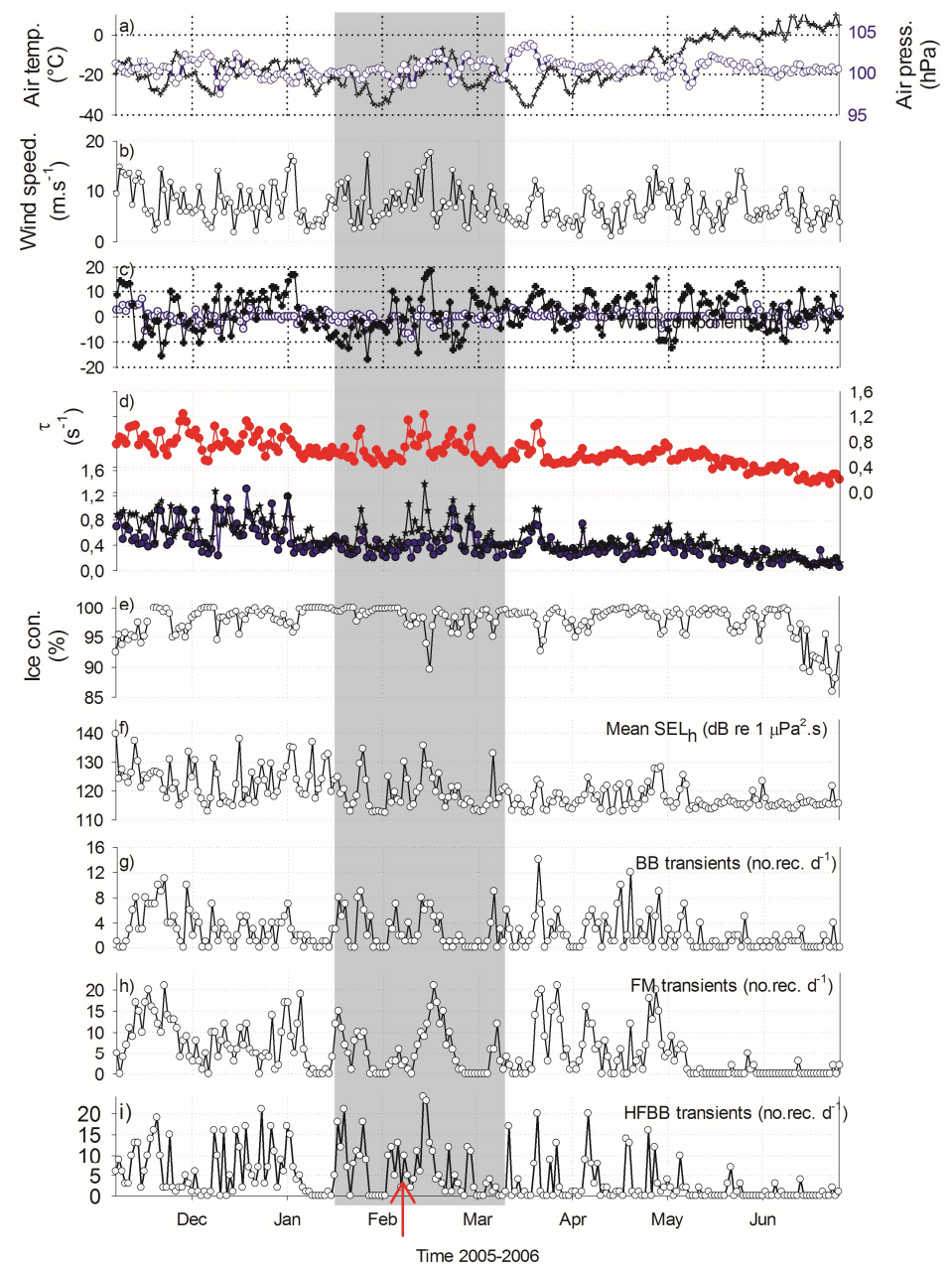

FIG. 5. (Color online) Under-ice time series of (a) air temperature (crosses) and pressure (circles), (b) wind speed with (c) its decomposition into easterly (line with crosses) and northerly (line with circles) components, (d) the mean ice deformation rate (_s) in MYI (line with stars), in FYI (line with filled circles), and the 1270_1330km wide Beaufort-Chukchi seas area (offsetted upper line with circle), right $\mathrm{Y}$ axis, (e) the local ice concentration in a radius of $100 \mathrm{~km}$ around the mooring position in the Amundsen Gulf mouth; (f) the SE_Lh, and the daily occurrences of (g) BB transients, (h) FM tonal transients, and (i) HFBB transients. The gray rectangle indicates the zoomed section in Fig. 7, the arrow at the bottom indicates the time of Fig. 8.

\section{Discussion}

The ice sheet is the most important noise source in ice-covered waters. This solid atmosphere-ocean interface experiences mechanical deformations by both internal and external forcings. Arctic Ocean noise is thus seasonally modulated by the air temperature, wind, and sea ice characteristics (thickness, age, continuous, broken, shore-fasten or moving) (Urick, 1984; Lewis and Denner, 1988). Under continuous ice sheet conditions in Arctic Ocean and Sub-Arctic Seas, the primary under-ice source of impulsive noise is the response of the ice cover to the atmosphere cooling, known as thermal cracking. Acoustic transients 
from such events are very short bursts consisting of a decaying sinusoid, lasting few milliseconds, and which spectrum has a broad maximum in the 0.1-1 kHz frequency decade (Ganton and Milne, 1965; Urick, 1984). Cummings et al. (1989) showed that, in very shallow waters, thermal cracking impulses lasted 0.1-0.3 s including reverberations. The thermal cracking itself occurs at the top few centimeters of the ice sheet where the maximum thermal stress takes place (Ganton and Milne, 1965) and decays exponentially with depth and runs over distances of the order of meters or tens of meters (Xie and Farmer, 1991; Zakarauskas et al., 1991). The individual acoustic transients resulting from thermal cracking are therefore local and radiate little energy (Cummings et al., 1989; Zakarauskas, 1993). Such short and weak events were observed, but they were not considered in our analysis.

TABLE V. Pearson correlations matrix between the variables. $\mathrm{T}=$ air temperature, wind $=$ wind speed; press $=$ air pressure, $\mathrm{IC}=$ ice concentration, ice deformation rates $(d=$ divergence, $s=$ shear; $\tau=$ total deformation), and daily occurrence of acoustic transients (BB; FM tones; HFBB). The ice concentration is computed for a $100 \mathrm{~km}$ radius around the mooring station, FYI = first year ice, MYI = multiyear ice; undelined values $\left(p<0.05\right.$, bold $\left(r^{2} \geq 0.10\right)$

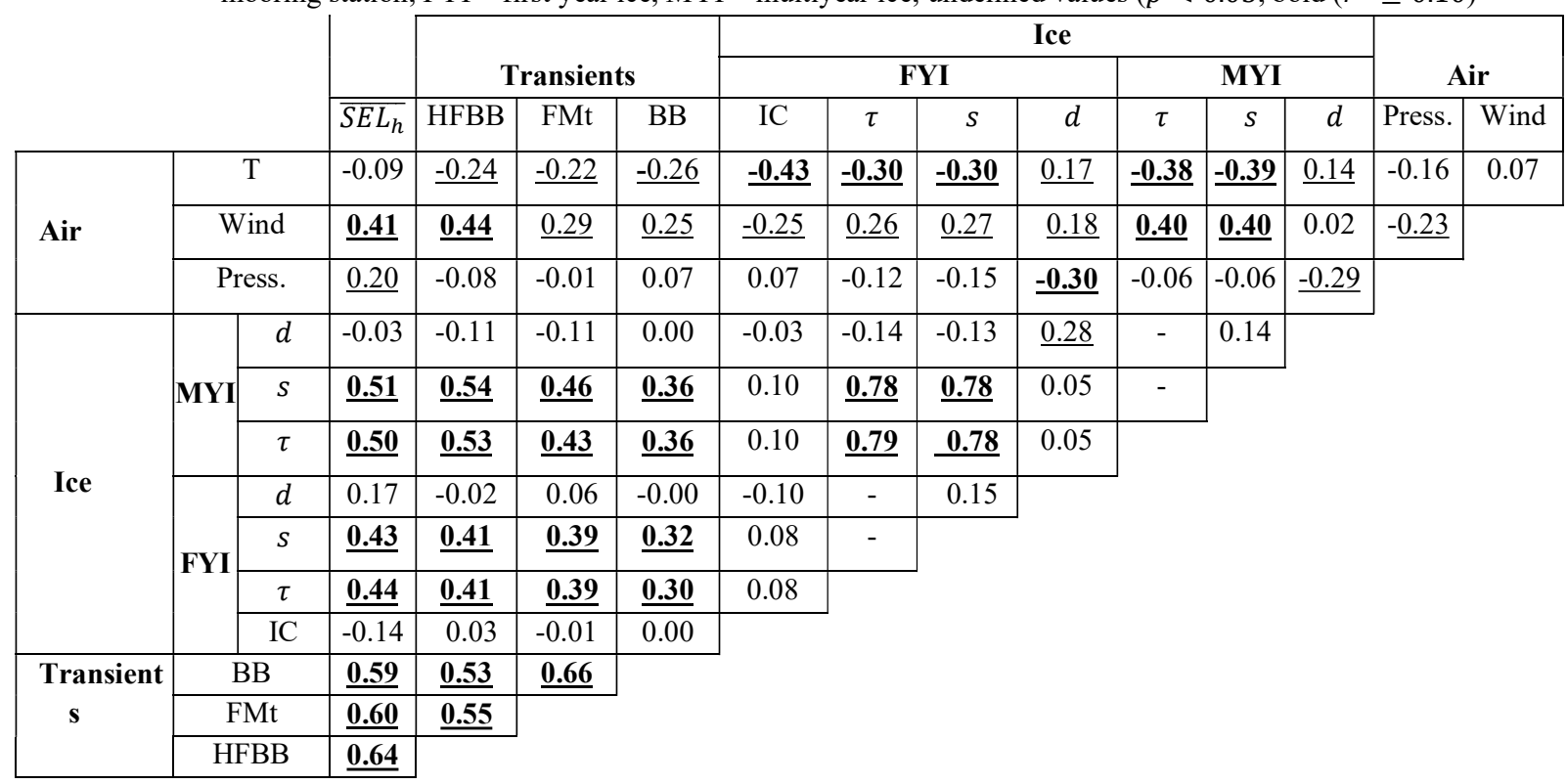

\section{A. Interpretation of transient classes}

\section{Class 1: BB transients}

We conclude that our BB transients can be considered as indicators of intensive ice fracturing, accompanying lead openings and networks of secondary cracks. In fact, Arctic sea ice deformation is a complex process involving winds, ocean currents, Coriolis Force, sea surface tilt, tide, and thermal strains induced by rapid variations of the air temperature (Weiss and Marsan, 2004; Marsan et al., 2004). The external forcings control the development of internal stress in the sea ice and its relaxation through viscous flow (Schulson and Hibler III, 1991, 2004). Temporally, the sea ice deformation is structured in strongly episodic sequences of deformation and fracturing, which are characterised in space by leads opening (Weiss 
and Marsan, 2004; Marsan et al., 2004). Xie and Farmer (1992) observed that lead opening (the fracturing of the layer of ice in its full thickness over distances of several kilometers) in landfast ice in Amundsen Gulf produces loud acoustic transient events. They associated particular transient sounds to three sequential phases of the ice breaking process. First, individual sound pulses are emitted, as the ice starts breaking on its weaker regions. Second, if the stress induced by the wind and/or the current continues, the ice keeps breaking and produces series of impulsive sounds radiating into the water. Third, some pure tone signals due to the ice rubbing induces shear waves in ice plate, whose resonance is transmitted to water.

Our BB transients were similar to the ice fracturing sound pulses corresponding to the first two phases of the breaking process. Series of such loud impulsive events of various durations repeated over several days. Due to our discontinuous recording, with a $12 \%$ duty cycle, we did not capture the whole process but only short samples. Similarly, satellite images of ice concentration are refreshed on a daily basis only; such snapshots do not allow the observations of the dynamics of the large lead opening that occurred between images, such as the one of February 5 and 6, 2006 (Fig. 8). This satellite-detected large lead was probably accompanied by some secondary leads and cracks that could not be detected with the coarse spatial resolution of the ice concentration images. This low resolution could explain the lack of detected leads in the second half of January (from map time series not shown) although acoustics transients were observed (Fig. 7a). The BB transient spectra (Fig. 2) had a peak frequency similar to those attributed to bumps of ice chunks and collision of ice crystals during ice break-up by Cummings et al. (1989) for shorter transients $(0.04-1.4 \mathrm{~s})$ than ours $(0.9->420 \mathrm{~s})$.

\section{Class 2: FM tonal transients}

Part of the FM transients shown on Fig. 3 was observed on February 12, 2006 corresponding to the re-opening of the previously developed large leads. Xie and Farmer (1992) associated these pure tones (778 $\mathrm{Hz}$, in their case) they observed during the ice break-up in landfast ice to the dry friction between the newly formed ice floes sliding along longitudinally and rubbing against each other. Ye (1995) later showed that the resonance of the shear horizontal $(\mathrm{SH})$ waves within the ice floes, generated by the roughness of interacting surfaces, may generate the pure tones and that shearing speed can determine their frequency. Our FM tonal transients were not confined to a single frequency and were sometimes mixed with impulses sounds. The observed FM tonal transients generally had a low-frequency fundamental and several harmonics which may extend beyond $4.1 \mathrm{kHz}$. The good correlation (Pearson $\mathrm{r}=0.66$ ) between BB transients and FM tonal transients suggests close links in their production mechanism. The relatively high correlation of FM tonal transient time series with the ice shear deformation rate, and the relatively long duration of these transients support a slow generating process, compatible with ice shear. Some FM tonal transients were short and repeated with periods similar to that of ocean waves. This suggests some interactions of the wind-waves generated in the large leads and ice fractured areas with ice floes rubbing. The tonal frequency of the transients was generally modulated with such periodicity and might also be related to the effect of waves on the ice shear speed.

\section{Class 3: HFBB transients}

The characteristics of the HFBB transients recall the well-known noise type generated by rain and wind in open water environments (e.g. Ma et al., 2005; Ma and Nystuen, 2005). It is tempting to attribute this high frequency noise to the snow pelting on the ice cover. However, precipitations recorded at the weather stations in this region are low (average $0.52 \mathrm{~cm}$ and $0.16 \mathrm{~cm}$ at Paulatuk $\left(69^{\circ} 21^{\prime} 40^{\prime \prime} \mathrm{N}, 124^{\circ} 04^{\prime} 31^{\prime \prime}\right.$ 
W) and Sachs Harbour (71'59'33” N, $125^{\circ} 15^{\prime} 15^{\prime \prime}$ W) respectively). Snow fall data recorded at Tuktoyaktuk and Cape Parry weather stations when HFBB transients of Fig. 4 were recorded, on February 12, 2006, did not indicate significant snowfall. Conversely, February 12 corresponded to the re-opening of the large lead along the Canadian coast, in Southeastern Beaufort Sea and Amundsen Gulf. The leads remained open for several days and the ice concentration in Amundsen Gulf around the mooring position (Fig. 5e, map time series not shown) showed that large areas were not completely covered by ice (ice concentration $=\sim 80 \%$ ). Leads closing involves two processes: the freezing of the free surface and the movement of the ice floes on either sides of the lead. In the surface freezing process, and under super cooling conditions, ice crystals (frazil ice) are formed first and then aggregate into pancake ice (Thomas and Dieckmann, 2010). Moreover, Arctic Sea ice concentration consists of 5-20\% of frazil ice (Thomas and Dieckmann, 2010). Predominant winds blow along the main axis of the leads and HFBB transients were shown to be highly correlated with wind speed. We therefore suggest that HFBB transients were produced by wind effects on the frazil ice. The occasional pulsed nature of such noise (e.g. Fig. 4b) may then be caused by the wind generated waves in the leads.

\section{B. Regional sea ice dynamics and underwater sound}

The low correlations found between transient occurrences and the air temperature in the Amundsen Gulf are not supportive of thermal stress origin for the three transients classes considered in the present study. The PCA analysis and the correlations showed that the acoustic transients were related to the ice mechanical deformation rate, mainly the shear within the MYI plume. This MYI plume was entrained by the Beaufort Gyre large-scale anticyclonic (clockwise) circulation. The induced ice deformation caused the ice cover to fracture where it presented faults, notably at the margin of landfast FYI, where the large-scale lead in Beaufort-Chukchi seas often opens and closes during winter under favorable wind pulses (cf. time series of ICDC satellite image ice concentration, not shown). The ice concentration did not correlate with either the ice deformation processes, nor with the acoustic transients. This suggests that the acoustic transients occurred prior to lead openings observed from satellite. Our result is therefore consistent with Weiss and Marsan, (2004)'s postulation that the most significant sea ice fracturing features are associated with ice shear deformation. The high variability of BB transient durations then reflects the multiscale structure of the ice cover fracturing.

The FM tonal transients may rely not only on the shear or rubbing between moving ice blocks but also on the multi-scale physical integrity of the ice cover throughout the seasonal ice covered period. As demonstrated by Xie and Farmer (1992) and later by Ye (1995), the frequency of the pure tones depends on the characteristics of the ice cover. Consequently, they depend on the period of the year, which contributes to explain the observed large dispersion in the bandwidth FM tonal transients (Table III). FM tonal transient occurrences vanished when the ice cover broke up, and the number of ice floes likely increased. This was also observed during the second half of February (Fig. 7c-2) where the ice cover maps showed an increase in the number of leads. Although there were an intense shear activity and numerous lead openings, the occurrences of the acoustic transients were low, including FM tonal transients. During this period, the fragmented ice cover in the Beaufort Sea basin would have facilitated the ice motion, resulting in high ice speeds and therefore high ice shear deformation rates (map time series not shown). This may not have resulted in higher occurrences of acoustics transients because the high fragmented nature of the ice cover did not favor the increase of internal stress. 

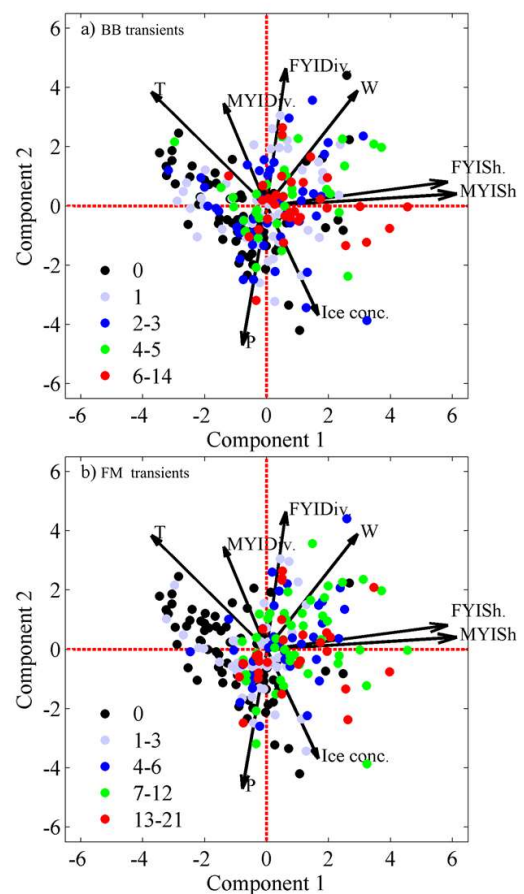

FIG 6. Scatter plot of scores of the PCA of the environmental variables in the space of the first two principal components, along with the factor loadings for each environmental variable, with color coding for the daily occurrence of: (a) BB transient, (b) FM tonal transients, and (c) HFBB transients. Ice Con., ice concentration; $\mathrm{P}$, air pressure; $\mathrm{T}$, air temperature; W, wind speed; FYIceDiv.,first year ice divergence; MYIceDiv., multi-year ice divergence; FYIceSh., first year ice shear deformation; MYIceSh., multiyear ice shear deformation

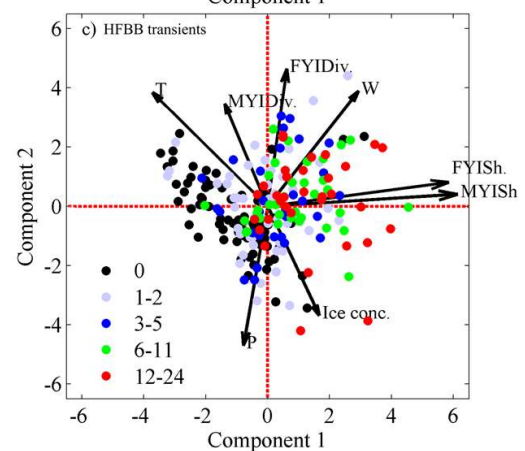



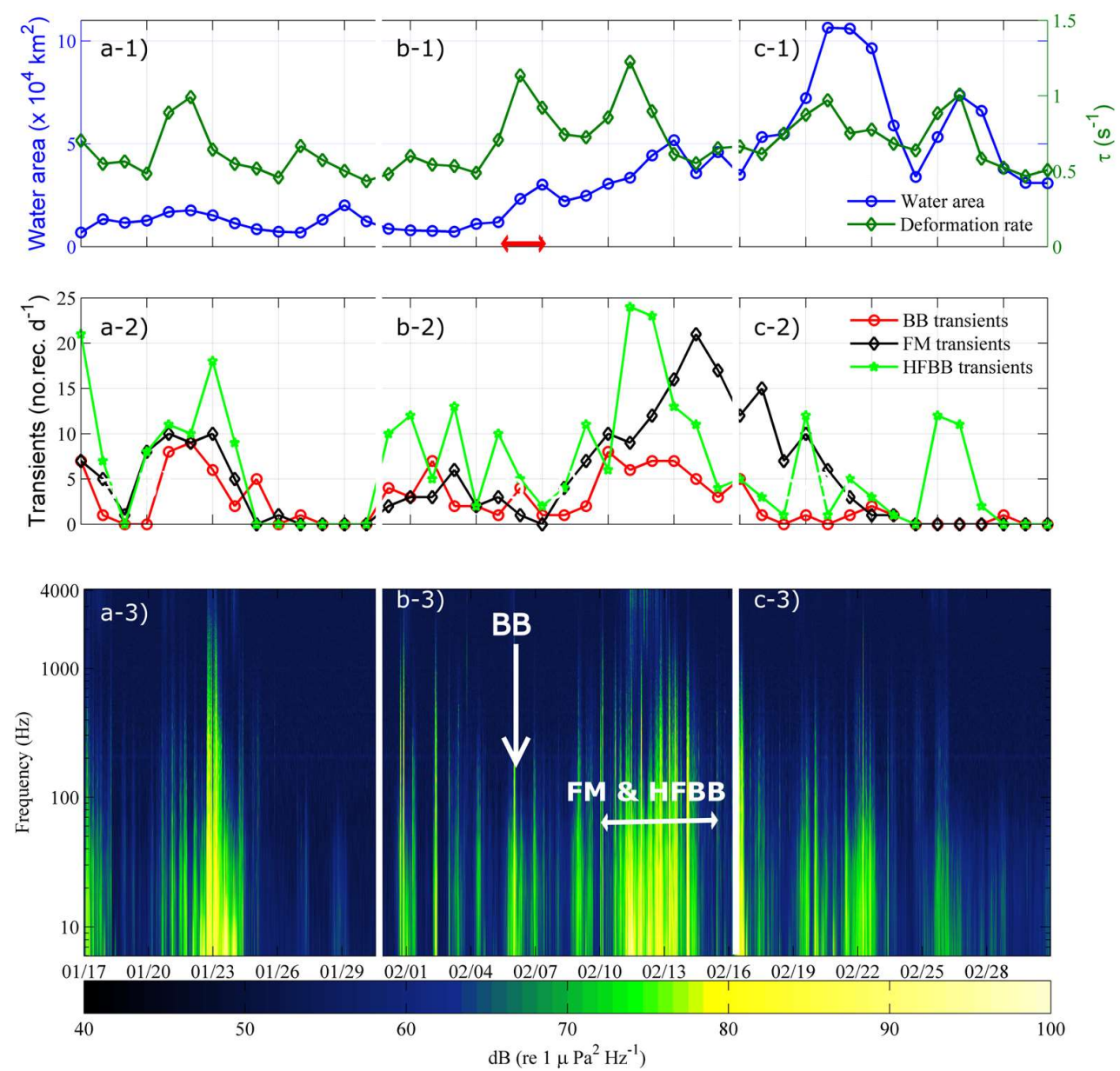

FIG 7. (Color online) Large-scale Beaufort-Chukchi seas daily changes in mean ice deformation and open water indexes [(a-1), (b1), (c-1)], corresponding acoustic transient occurrences [(a-2), (b-2), (c-2)], and spectrogram [(a-3), (b-3), (c-3)] of a 45-day period showing episodes of acoustic events lasting several hours in the Amundsen Gulf mouth for: (a) January 17-31, (b) February 1-15, and (c) February 16-March 2, 2006. Arrow in (b-1) indicates the time of Figs. 8(b) and 8(d), and arrows in (b-3) indicate the time of transients shown in Figs. 2(b), 3(a)-3(e), and 4.

\section{Under-ice soundscape and SEL from natural sources in the Arctic}

The observation that the ice acoustic transients originated from ubiquitous multi-scale processes operating across the entire Arctic Ocean agrees with our previous conclusions for similar forcings determining the ANL of the under-ice soundcape (Kinda et al., 2013). Except for the 5\% highest level transients, the added contribution of the ice transient sounds to get the under-ice soundscape ONL only changes the level by less than $1 \mathrm{~dB}$ in most (75\%) cases where transients were present (ONL-ANL, Tables II, III, IV). There are two possible reasons for these results: a) transients are short compared to the persistent background ambient noise, and b) the ANL is increasing when the transient occurrence increases (Pearson $r \geq 0.48$ ), because noise from distant transient sources merges to make the ambient noise background (c.f. Kinda et al., 2013). The ONL ( $>111 \mathrm{~dB}$ re $1 \mu \mathrm{Pa}$ ) of the $5 \%$ recordings with the strongest transients is as high as the median ONL observed on a medium traffic seaway (112 dB re $1 \mu \mathrm{Pa}$, Simard et al., 2010). On average, BB transient levels exceed by $9-11 \mathrm{~dB}$ the levels of the other two transient classes. This frequent 
low-frequency impulsive type of sounds, which can reach $137 \mathrm{~dB}$ re $1 \mu \mathrm{Pa}$, is the transient type contributing the most to the highest noise levels of the under-ice soundscape. The HFBB transients are the less energetic ones because of their high-frequency, but when present they can change the background noise in their frequency band by more than $20 \mathrm{~dB}$ (Fig. 4c). Due to the continuous nature of this type of transient, the possibility of masking calls from marine mammals using the same frequency band is significant.

Although some of them can be energetic, the frequent FM tonal transients consisting of narrow frequency contours did not contribute much to ANL or ONL. Their tonal and FM nature with frequent harmonics may sometimes lead to the misidentification with similar tonal sounds and songs produced by marine mammals. Bowhead whales songs in the same frequency band were observed by Stafford et al. (2008, Fig. 3, 5, Table II) and by Tervo et al. (2011, Fig. 3). They differ from our FM tonal transients by shorter durations and presence of well-defined repeated song themes. More recently, Magnúsdóttir et al. (2014) identified several acoustic transient patterns as Humpback whale songs from long-term acoustics mooring in Northeast Iceland. These authors report a lack of repeatability during the winter in a proportion of the detected acoustic signals, which was attributed to their short recording duration (1-min sound every $15 \mathrm{~min}$ ), which was insufficient to obtain the whole themes. Our observations of frequent FM tonal transients with no repeated themes argue for caution in attributing such winter appearances of unpatterned tonal sounds in icy waters to biological sources.

In conclusion, under-ice sound transients originating from ice dynamics in the Arctic Ocean were characterized using an acoustic time series covering a complete annual cycle in Southeastern Beaufort Sea. Their links with external forcings and generating mechanisms were explored with meteorological data and large-scale ice characteristics, motion and deformation. To our knowledge, it is the first time such a comprehensive approach has been used to study the acoustic transients of the underwater soundscape of the Arctic Ocean. Under-ice acoustic transients were separated in 3 different classes. The class 1 broadband impulsive transients corresponding to ice fracturing occurred $10.6 \%$ of the time. Their peak energy was generally below $100 \mathrm{~Hz}$ and their SPL averaged $104 \mathrm{~dB}$ re $1 \mu \mathrm{Pa}$. These transients significantly contribute to shape both the ambient and total noise components of the under-ice Arctic soundscape. Class $2 \mathrm{FM}$ tonal transients corresponding to ice shearing and rubbing were twice as frequent, covered a wide range of frequencies and their SPL averaged $95 \mathrm{~dB}$ re $1 \mu \mathrm{Pa}$. The class 3 high-frequency transients attributed to frazil noise were encountered $18.5 \%$ of the time, generally confined to frequencies $>\sim 1.5 \mathrm{kHz}$, and their SPL averaged $93 \mathrm{~dB}$ re $1 \mu \mathrm{Pa}$. The exposure levels (SEL) to these natural sounds of the Arctic, were estimated. The SEL strongly correlated with all transient occurrences. All transient classes correlated with ice shear deformation rate but not with ice concentration. Burst of ice deformation in Beaufort-Chukchi seas were sometimes followed by recurrent large-scale lead openings at the margin of landfast ice and MYI plume under favorable wind forcing. The low resolution of the satellite tracked ice concentration image $(25 \times 25$ $\mathrm{km}$ ) could not detail the secondary fracture and crack network. Acoustic recording provides continuous temporal data that can advantageously complement the discontinuous synoptic information from satellite images in combination with other environmental data in studying and monitoring these dynamic ice processes occurring in a rapidly changing Arctic Ocean under global warming. 

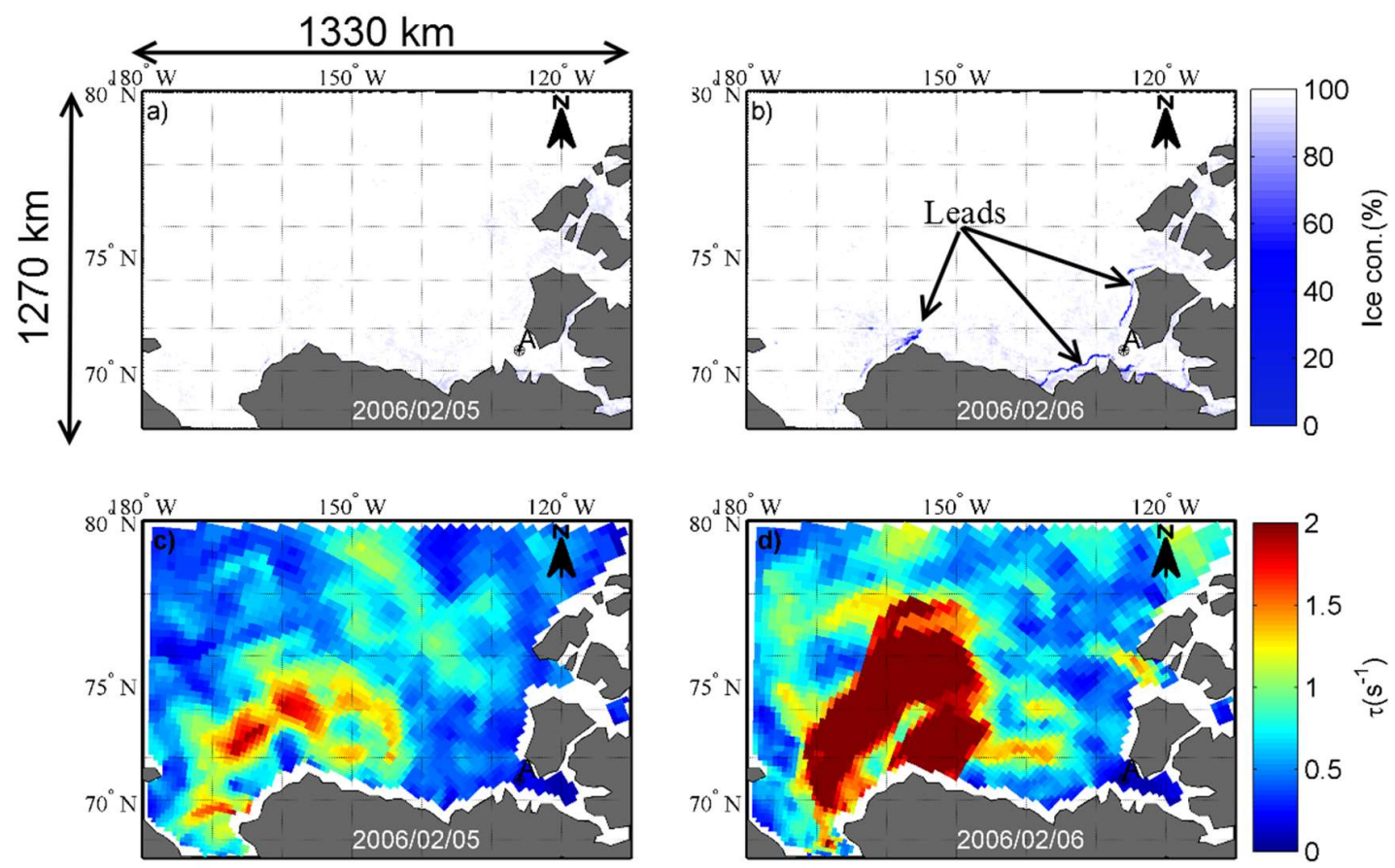

FIG. 8. Example of large-scale ice deformation during easterly winds and opening of leads in Beaufort-Chukchi seas MIZ area associated with surges of transient noise at the mouth of the Amundsen Gulf. (a) and (b) Ice concentration maps and (c) and (d) ice deformation field for February 5 and 6 , showing the opening of $>300 \mathrm{~km}$ long $x$ tenths of km wide leads in the MIZ on February 6.

\section{ACKNOWLEDGMENTS}

Grants from the Natural Sciences and Engineering Research Council of Canada, the Network of Centres of Excellence ArcticNet and the Fonds québecois de recherche nature et technologie to Y.S. and L.F., and from Europôle Mer and Exploradoc CMIRA from Région Rhône-Alpes to B.G.K, C.G. and J.I.M are gratefully acknowledged.

\section{References}

Buck, B.M., and Wilson, J.H. (1986). "Nearfield noise measurements from an Arctic pressure ridge," J. Acoust. Soc. Am. 80, 256-264.

Cummings, W. C., Diachok, O. I., and Shaffer, J. D. (1989). "Acoustic Transients of the Marginal Sea Ice Zone: A Provisional Catalog (No. NRL-MR-6408)," Technical report, Naval Research Lab, Washington DC.

Ganton, J. H., and Milne, A. R. (1965). "Temperature and Wind Dependent Ambient Noise under Midwinter Pack Ice,” J. Acoust. Soc. Am. 38, 406-411.

Kinda, G. B., Simard, Y., Gervaise, C., Mars, I. J., and Fortier, L. (2013). "Under-ice ambient noise in Eastern Beaufort Sea, Canadan Arctic, and its relation to environmental forcing," J. Acoust. Soc. Am. 134, 77-87.

Kwok, R., and Cunningham, G. F. (2012). "Deformation of the Arctic Ocean ice cover after the 2007 record minimum in summer ice extent," Cold Regions Science and Technology 76, 17-23.

Kwok, R. (2001). "Deformation of the Arctic Ocean sea ice cover between November 1996 and April 
1997: a qualitative survey," Solid Mechanics and its Applications 94, 315-322.

Legendre, P., and Legendre, L. (1998). Numerical ecology. Numerical Ecology. Developments in Environmental Modeling (Elsevier, Amsterdam, The Netherlands), Vol.20

Lewis, J. K., and Denner, W. W. (1987). "Arctic ambient noise in the Beaufort Sea: seasonal space and time scales", J. Acoust. Soc. Am, 82, 988-997.

Lewis, J.K., and Denner, W.W. (1988). "Arctic ambient noise in the Beaufort Sea: Seasonal relationships to sea ice kinematics," J. Acoust. Soc. Am. 83, 549-565.

Ma, B. B., and Nysten, J. A. (2005). "Passive acoustic detection and measurement of rainfall at sea," J. Atm. Oceanic Tech. 22, 1225-1248.

Ma, B. B., Nysten, J. A. and Lien, R.-C. (2005). "Prediction of underwater sound levels from rain and wind," J. Acoust. Soc. Am. 117, 3555-3565.

Magnúsdóttir, E. E., Rasmussen, M. H., Lammers, M. O., and Svavarsson, J. (2014). "Humpback whale songs during winter in subarctic waters," Polar Biology 37, 427-433.

Marsan, D., Stern, H., Lindsay, R., and Weiss, J. (2004). "Scale dependence and localization of the deformation of Arctic sea ice," Phys. Rev. Lett., 93, 178501.

Marsan, D., Weiss, J., Larose, E., and Metaxian, J. P. (2012). "Sea-ice thickness measurement based on the dispersion of ice swell," J. Acoust. Soc. Am. 131, 80-91.

Maslanik, J., Stroeve, J., Fowler, C., and Emery, W. (2011). "Distribution and trends in Arctic sea ice age through spring 2011," Geophys. Res. Lett. 38, L13502.

Milne, A.R. (1966). "Statistical description of noise under shore fast sea ice in winter," J. Acoust. Soc. Am. 39, 174-1182.

Milne, A. R., and Ganton, J. H. (1964). "Ambient noise under Arctic sea ice," J. Acoust. Soc. Am. 36, $855-863$.

NRC (2003). “Ocean noise and marine mammals, " National Academies Press, Washington D.C, (US).

Rampal, P., Weiss, J., Marsan, D., Lindsay, R., and Stern, H. (2008). "Scaling properties of sea ice deformation from buoy dispersion analysis," J. Geophys. Res., 113, C03002.

Schulson, E. M., and Hibler III, W. D. (1991). "The fracture of ice on scales large and small: Arctic leads and wing cracks," J. Glac. 37, 319-322.

Schulson, E. M., and Hibler III, W. D. (2004). "Fracture of the winter sea ice cover on the Arctic Ocean," Comptes Rendus Physique 5, 753-767.

Simard, Y., Lepage, R., and Gervaise, C. (2010). "Anthropogenic sound exposure of marine mammals from seaways: Estimates for lower St. Lawrence Seaway, eastern Canada," Appl. Acoust. 71, 1093-1098.

Stafford, K. M., Moore, S. E., Laidre, K. L., and Heide-Jørgensen, M. P. (2008). "Bowhead whale springtime song off West Greenland," J. Acoust. Soc. Am. 124, 3315-3323.

Stroeve, J. C., Serreze, M. C., Holland, M. M., Kay, J. E., Malanik, J., and Barrett, A. P. (2012). "The Arctic's rapidly shrinking sea ice cover: a research synthesis," Climatic Change 110, 1005-1027.

Tervo, O. M., Christoffersen, M. F., Parks, S. E., Kristensen, R. M., and Madsen, P. T. (2011). "Evidence for simultaneous sound production in the bowhead whale (Balaena mysticetus)," J. Acoust. Soc. Am.130, 2257-2262.

Thomas, D. N., and Dieckmann, G. S. (2010). "Sea ice (Second Edition)," Wiley-Blackwell (A John Wiley $\&$ Sons, Ltd, Publication).

Urick, R.J. (1984). "Ambient noise in the sea". Technical report, Undersea Warfare Technology Office, Naval Sea System Command, Department of the Navy, Washington, D.C.

Veitch, J. G., and Wilks, A. R. (1985). "A characterization of arctic undersea noise,” J. Acoust. Soc. Am. 
77, 989-999.

Weiss, J., and Marsan, D. (2004). "Scale properties of sea ice deformation and fracturing," Comptes Rendus Physique 5, 735-751.

Xie, Y., and Farmer, D. M. (1991). “Acoustical radiation from thermally stressed sea ice,” J. Acoust. Soc. Am. 89, 2215-2231.

Xie, Y., and Farmer, D. M. (1992). "The sound of ice break up and floe interaction," J. Acoust. Soc. Am. 91, 1423-1428.

Xie, Y., and Farmer, D. M. (1995). "The influence of pressure ridges on seismic signals due to thermal cracking of sea ice," J. Acoust. Soc. Am. 97, 962-970.

Ye, Z. (1995). "Sound generation by ice floe rubbing," J. Acous. Soc. Am. 97, 2191-2198.

Zakarauskas, P., Parfitt, C.J., and Thorleifson, J.M. (1991). "Automatic extraction of spring time Arctic ambient noise transients," J. Acoust. Soc. Am. 90, 470-474.

Zakarauskas, P. (1993). "Detection and localization of nondeterministic transients in time series and application to ice-cracking sound," Digital Signal Processing 3,36-45. 